\title{
CHANGES IN DISTRIBUTION AND STRUCTURE OF WILD MELISSA OFFICINALIS L. POPULATIONS DURING THE LAST DECADE IN ARMENIA AND IMPLICATIONS FOR CONSERVATION
}

\author{
Armine Abrahamyan \\ Armenian State Agrarian University, Horticultural Department \\ Yerevan, Teryan 74, 009 Armenia \\ Rezekne's Augstskola, Engineering Faculty \\ Ph.: +(371) 25855196, e-mail: arm_abrahamyan@yahoo.com
}

\begin{abstract}
Armenia has a strong interest in examining the biodiversity of native plant species and assessing their conservation status. Anthropogenic threats to this biodiversity such as overpopulation, deforestation and urbanization have simultaneously hindered research and increased the need for it. Only limited information on the genetic biodiversity, population location, structure and size, and conservation status of most of these species is, however, at this time available. During 2006-2009, field studies were conducted to re-locate populations of wild Melissa officinalis L. on the basis of historical (i.e. herbarium voucher) records, and to discover new populations. The growth, phenological and habitat characteristics of the plant, and overall populations size were assessed. GPS map of present and past population distribution were created. This research provided baseline data that can be used for the development of further ex situ and in vitro strategies to conserve unique genotypes, as well as to assess the sustainability of wild populations with regard to the IUCN Red Book Criteria, of this important medicinal and culinary species in Armenia.
\end{abstract}

Key words: wild, medicinal plant, conservation, new population.

\section{Introduction}

The small mountainous country of Armenia has a rich flora of ca. 3600 species of vascular plants, which makes about half of entire Caucasian flora, with both Caucasian and Iranian elements, distributed across desert and semi-desert, steppe, forest and alpine landscapes. As one of the first countries to join the Convention on Biological Diversity (CBD), Armenia has a strong interest in examining the biodiversity of native plant species, particularly those with potential or existing economic value (e.g. medicinal plants), and assessing their conservation status (1). Anthropogenic threats to this biodiversity such as overpopulation, deforestation and urbanization have simultaneously hindered research and increased the need for it. Of the ca. 500 species in the Armenian flora with a record of medicinal and/or economic use, ca. 50 species are used in the folk medicine and include both wild-collected

(Crataegus sp., Hypericum perforatum, Artemisia absinthium) and cultivated (Chamomilla recutita, Mentha piperita, Crocus sativus) species (2). Only limited information on the genetic biodiversity, population location, structure and size, and conservation status of most of these species is, however, at this time available.

\section{Materials and methods}

Melissa officinalis L. belongs to Lamiaceae family. The wild form of plant is native to Northern Africa, Caucus, South western Asia, Europe, Persia and Mediterranean regions. In Armenia it grows only in a wild form. There are no records about its cultivation in Armenia. It grows wild from 600 to 1600 elevations in Aragats, Igevan, Zangezur and Mekhri floristic regions (3). I have been collaborated with "Environmental Conservation and Research Centre" of American University of Armenia and „Botanical Garden” of National Science Academy. During 2006-2009, field studies were conducted to re-locate populations of wild Melissa officinalis L. on the basis of historical (i.e. herbarium voucher) records, and to 
discover new populations. The selection of researching territories has been realized by taking into account the existing data (The Botanic Garden of RA) and theoretically possible existence of new population. These territories vary with their geographical location, elevation, soil types, climatic conditions etc.

The growth, phenological and habitat characteristics of the plants, and overall population size were assessed. GPS maps of present and past population distribution were created. During the growing seasons we have realized many field trips almost all regions of Armeniaa. Our goal is to create vulnerable data about wild Melissa officinalis L., which in turn would provide as a basic material for its future domestication experiments in Armenia.

\section{Results and Analysis}

In the results of conducted field trips and expeditions, it has been identified the changes in respect with the distribution and abundance of Melissa officinalis L. Populations, as well as drew new pattern for it. So, the following map demonstrates this plant populations changes during last decade, as well as the current condition.

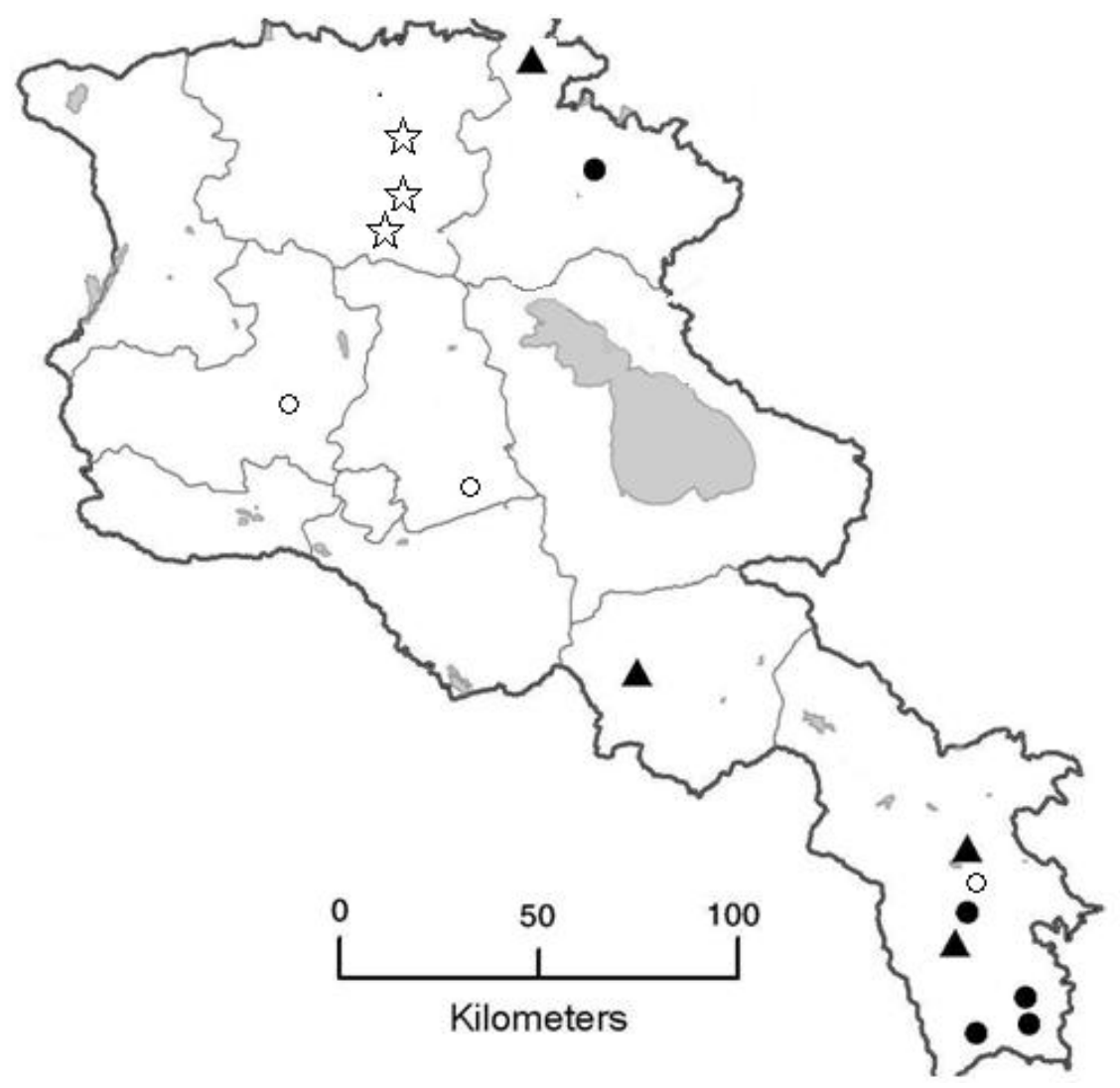

Fig.1. Distribution and Changes of Wild Melissa Officinalis L. Populations

(in regard with implemented field trips in 2006-2009)

- existing population

$\Delta$ new population

$\circ$ reducing or/and eliminating population

in extinct population

Even though, historical records indicated that this wild plant's populations had been widely distributed in the northern and central regions of Armenia, nearly half of the populations no longer existed in cited locations. Remaining populations in these regions displayed trends of reduction in overall size, during the study period. 3 new populations were located in the south regions and 1 new population in the northern region of the country, and evidence that the 
abundance and distributional range of Melissa officinalis $L$. is expanding in the southern region was collected.

Some anthropogenic threats that were identified as part of the study included poor land management (erosion, overgrazing), increasing population pressure (impact of livestock overpopulation, improper human development), and excessive or inappropriate collection for the purposes of local sale/usage (due to lack of knowledge/training of collectors).

Realized different multiple observations over the populations have exposed phenological and habitat characteristics of the plants as well as assessed population size, its abundance and the number of ripen plants. The following table shows certain data in respect with them.

Populations' Sizes, Abundance, Plant Highness, Grow intensity

Table 1.

(Estimations have been done according to the average data of 15 plants)

\begin{tabular}{|c|c|c|c|c|c|c|}
\hline \multicolumn{2}{|c|}{ Population } & \multirow{2}{*}{$\begin{array}{l}\text { Size, } \\
m^{2}\end{array}$} & \multirow{2}{*}{$\begin{array}{c}\text { Location, } m \\
\text { (above sea level) }\end{array}$} & \multirow{2}{*}{$\begin{array}{l}\text { Density, } \\
\text { plant/1m }\end{array}$} & \multirow{2}{*}{$\begin{array}{c}\text { Plant } \\
\text { highness, } \\
\text { cm }\end{array}$} & \multirow{2}{*}{$\begin{array}{c}\text { Stems } \\
\text { quantity/plant }\end{array}$} \\
\hline Region & Place & & & & & \\
\hline Aragatsotn & Orgov & 95 & 1610 & 1 & 80 & $1-3$ \\
\hline Kotayq & Garni & 90 & 1310 & 1 & 70 & $1-3$ \\
\hline Vajoc Dzor & Germuk & 480 & 2104 & 5 & 145 & $2-5$ \\
\hline \multirow{2}{*}{ Tavush } & Getahovit & 210 & 905 & 4 & 100 & $2-3$ \\
\hline & Ajrum & 165 & 375 & 2 & 95 & $1-3$ \\
\hline \multirow{3}{*}{ Sjuniq } & Artsvanic & 250 & 1666 & 4 & 100 & $3-7$ \\
\hline & Srashen & 520 & 1025 & 6 & 150 & $3-7$ \\
\hline & Shikahogh & 280 & 957 & 3 & 65 & $2-5$ \\
\hline
\end{tabular}

So, if we draw analysis from table 1, populations, in the central part of the country (Aragatsotn, Kotayq), do not demonstrate intensive grow capability, they are small with their overall sizes, number of plants etc. In fact, the study shows that there are many factors, which affect negatively on the conservation of these populations (e. g. anthropogenic influence, climatic condition, plant habitat). What is more, the condition of these populations is now alarming in respect with frequently occurred early spring frost and the abrupt changes of weather in these areas. Study has shown that the seedlings of Melissa officinalis L. are very susceptible towards early spring frost, which prohibits their growing and affect negatively on the overall sizes, abundance of populations. By comparison, the populations growing in the northern part (Getahovit, Ajrum ) have middle overall sizes. However, it is obvious that in the southern part of the country they are flourishing. Study has shown, that here the plant exhibits high grow capacity and there is recorded the increase of populations abundance and distributions. In fact, it is connected with soil, weather and climatic conditions. The following table shows certain data in respect with it.

So, we have found out certain habitat or biological characteristics of this wild plant by the comparison and analysis of data based on historical and study records. In fact, Melissa grows very well in moisture, temperate climatic condition (southern regions of the country). In case of relatively low annual precipitation it exhibits drought-resistant capability. Though, wild Melissa grows in various soils, however it demonstrates high grow capacity in reach, slight mechanical structure and acid $\mathrm{pH}$ bearing soils. 
Table 2.

Soil Characteristic and Annual Precipitation

\begin{tabular}{|l|l|c|c|c|c|}
\hline \multicolumn{2}{|c|}{ Population } & $\begin{array}{c}\text { Genetic } \\
\text { zone of soil }\end{array}$ & $\begin{array}{c}\text { Annual } \\
\text { precipitation } \mathbf{~ m m}\end{array}$ & Soil pH & $\begin{array}{c}\text { Humus concentration, } \\
\text { \% }\end{array}$ \\
\hline Aragatsotn & Orgov & Steppe black & $470-530$ & 7 & $3-6$ \\
\hline Kotayq & Garni & Dry steppe & 430 & $6.9-8.1$ & $2-4$ \\
\hline \multirow{2}{*}{ Vajoc Dzor } & Germuk & $\begin{array}{c}\text { Mountain- } \\
\text { meadow }\end{array}$ & $900-1000$ & $4.8-5.5$ & $13-19$ \\
\hline \multirow{2}{*}{ Tavush } & Getahovit & Forest-gray & $570-750$ & $5-6$ & $5-9$ \\
\cline { 2 - 5 } & Ajrum & $\begin{array}{c}\text { Forest black } \\
\text { soil }\end{array}$ & 470 & $6-7$ & 4 \\
\hline \multirow{3}{*}{ Sjuniq } & Artsvanic & $\begin{array}{c}\text { Steppe black } \\
\text { soil }\end{array}$ & $700-900$ & $4.3-5.5$ & $11-12$ \\
\cline { 2 - 5 } & Srashen & $\begin{array}{c}\text { Steppe black } \\
\text { soil }\end{array}$ & $750-900$ & $4.2-5$ & $12-13$ \\
\cline { 2 - 5 } & Shikahogh & Steppe & $450-500$ & $5.1-6.2$ & $5-8$ \\
\hline
\end{tabular}

\section{Summary}

Although historical records indicated that populations of wild Melissa officinalis L. had been widely distributed in the northern and central regions of Armenia, nearly half of the populations no longer existed in cited locations. Remaining populations in these regions displayed trends of reduction in overall size, plant number and fragmentation during the study period. 3 new populations were located in the south regions and 1 new population in the northern region of the country, and evidence that the abundance and distributional range of Melissa officinalis $L$. is expanding in the southern region was collected. Melissa is droughtresistant, but grows better in soils with enough moisture. It is susceptible towards early spring frosts and abrupt weather changes. Also, it demonstrates high grow capacity in the temperate climatic condition as well as in reach, slight mechanical structure and acid $\mathrm{pH}$ bearing soils.

This research provided baseline data that can be used for the development of further ex situ and in vitro strategies to conserve unique genotypes, as well as to assess the sustainability of wild populations with regard to the IUCN Red Book Criteria, of this important medicinal and culinary species in Armenia. Created data could be served as indispensable materials for the appropriate approaches of domestication experiments of wild Melissa. This would foster the improvement of its conservation and use and the development of traditional medicine as well.

\section{References}

1. IUCN, WHO, WWF (1993). Guidelines on the Conservation of Medicinal Plants, IUCN, Gland, Switzerland, $50 \mathrm{p}$.

2. Fayvush, G., Danielyan T., Nalbandyan A. (2004) Armenia as a producer of medicinal plants: possibilities and perspectives. Available online (accessed 12 April 2010): http://www.nature-ic.am/NCSA/ Publication/ Medical_Plants_eng.pdf

3. Takhtajyan A.L., (1973), 8 section, "Flora of Armenia" Sciences National Academy of Armenia. 